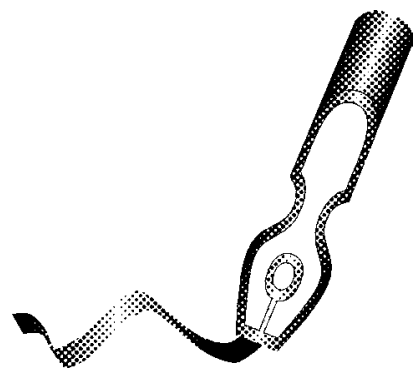

\title{
Proyecto de educación continua
}

Este proyecto ha sido presentado por una comisión a solicitud de la Sociedad de Otorrinolaringología, Medicina y Cirugía de Cabeza y Cuello al Consejo Docente y éste ha solicitado el proyecto presentado en el año 2004 con las modificaciones pertinentes y de acuerdo a la realidad actual.

La posibilidad de contar con un programa de educación continua está avalado por la necesidad de los tiempos modernos y será obligatorio por Ley de la República. Cada especialista deberá demostrar su acreditación como tal en un lapso de tiempo estimado de 8 años. Así, cada especialista, en un futuro, deberá demostrar un número de créditos anuales para acceder a dicha acreditación.

Un programa de educación continua es la oportunidad que tienen los especialistas de nuestra Sociedad de perfeccionar sus conocimientos y puesta al día en todos los adelantos científicos de la ORL. Es un proceso individual que cada cual realiza por sus propios medios. El programa de educación continua de la Sociedad, debe intentar mejorar y permitir que ese proceso sea aún más fluido. Este proceso lo ha favorecido y estimulado permanentemente nuestra Sociedad y en forma personal cada uno de sus integrantes pero, ahora debe ser perfeccionado, difundido y publicitado de una manera diferente.

El ejecutor del programa podría ser el Consejo Docente de una manera semejante al funcionamiento de un módulo con permanente evaluación y cambios, de acuerdo a las ideas y nuevas situaciones que se presenten. Se entiende que está dirigido sólo a los socios de nuestra Sociedad.

El proyecto está dividido en dos aspectos. El programa de educación continua en sí y la forma de evaluación.

El programa estará constituido por múltiples iniciativas algunas evaluables y otras no. La evaluación es la única manera de demostrar la vigencia al programa de Educación Continua. Independiente de la posibilidad de evaluación la idea es que cada socio disponga de la posibilidad de adherirse al proyecto de Educación Continua para lo cual dispondrá de:

1. Reuniones científicas especialmente las organizadas, patrocinadas 0 auspiciadas por la Sociedad Chilena de Otorrinolaringología, Medicina y Cirugía de Cabeza y Cuello. Los elementos más significativos de estas reuniones serán el Congreso Anual, Ios CEPE y la reunión de invierno. Se incluyen dentro de este punto 1, la asistencia a las clases teóricas del curso de becados y también participaciones de los socios en reuniones científicas internacionales y nacionales y las asistencias y participaciones en clases 0 cursos dictados dentro de los programas de las diferentes actividades académicas ORL, como también los realizados en otras instituciones. Esta parte del programa es completamente aplicable de inmediato y además será la evaluada inicialmente.

2. Programa de autoinstrucción. Este programa deberá ser implementado sobre temas específicos que el Comité irá desarrollando con una frecuencia a determinar. Para cumplir con este objetivo fundamental de nuestro proyecto se podrá solicitar el 
concurso de destacados especialistas en los temas propuestos. Esta parte debe implementarse en un plazo fijo el que podría ser en tres años.

3. Programa de estadía de capacitación práctica y reexaminación en determinados temas para socios. Este programa podrá desarrollarse en los centros formativos tradicionales de becados y en otros centros seleccionados como Santiago, Concepción y Valparaíso. Esta parte debe implementarse en un año. Una vez implementado se discutirá su valor en créditos.

4. Difusión escrita. Se entiende como tal el material de lectura escrita que sirva para el perfeccionamiento de cada socio. El programa entiende que la difusión escrita más significativa de cada socio es la publicación y lectura de nuestra Revista. Se debe recopilar toda la información que actualmente dispone la Sociedad y agregar los contenidos que se estimen necesarios. Esta parte del programa se puede realizar inicialmente en un año y luego actualización permanente.

5. Material audiovisual. Se entiende como tal el material audiovisual que sirva para el perfeccionamiento de cada socio. El programa de educación continua necesita como un punto fundamental material de consulta audiovisual, para una mejor capacitación de nuestros residentes y socios. Como tal entendemos operaciones, presentaciones audiovisuales, conferencias presentadas en Servicios ORL académicos y no académicos. El comité deberá solicitarlo. El o los autores deberán figurar como parte de él y podrán solicitar la certificación a la Sociedad. Esta parte debe implementarse. Solicitar información y recopilar toda la información disponible.

6. Clases del curso para residentes. Material importante para el programa de educación continua. Para implementarlo se requiere un sistema profesional de registro de la información entregada en cada clase. Sugerimos una grabación de la transmisión vía Internet que se implementará a partir del primer módulo del Curso del próximo año. Cada socio puede asistir a las clases y recibir créditos por esto. Esta parte debe implementarse a partir de la transmisión a Concepción vía Internet.

7. Programa de Educación Continua por Internet. La idea central de este punto es conectar al socio con expertos ocupando a la Internet. Sin duda que esto debe implementarse. Se debe desarrollar un programa de Educación Continua especial por Internet para provincia. Este debe incluir reuniones de expertos, videoconferencias, discusión de casos clínicos. Creemos que se debe constituir un comité de destacados especialistas en un tema especial. Por ejemplo, en oído el comité de asesoría de resolución de diferentes problemas clínicos podrían estar constituido (en forma voluntaria) por cinco miembros. Ellos reciben un mail de provincia de un determinado colega solicitando una opinión y este comité, en forma individual y desde su casa, contesta también por mail. Los comités deberían ser los mismos de los diferentes módulos. En total 8 comités (audiología, otoneurología, patología de oído, rinosinusología, patología benigna de vía respiratoria, patología de la voz, patología maligna de cara y cuello y patología traumática de cabeza y cuello).

Esta parte, junto a las otras del programa propuesto, debe implementar una organización profesional del tema de Educación Continua que incluya al menos un cargo remunerado.

El sistema de evaluación deberá considerar un sistema de créditos y el número necesario de éstos para ser acreditados. La evaluación presentada de esta manera tiene por objetivo incentivar la incorporación al programa, manteniendo de esta manera la perfecta capacitación de nuestros socios. Una consideración especial la constituye la situación laboral futura. Es posible que alguna institución deba ser garante de la real capacitación de un determinado ORL. Si esa situación se presentara a la Sociedad debería informar la capacitación de un determinado socio, informando con un adecuado y serio proceso los créditos acumulados del solicitado.

Dr. Jorge Caro Letelier 